\title{
Effect of chemical surface treatment on the mechanical properties of reinforced plasticized poly(lactic acid) biodegradable composites.
}

\begin{abstract}
Biodegradable composites were prepared by melt-blending technique using $30 \mathrm{wt} \%$ kenaf bast fiber (KBF) to reinforce $70 \mathrm{wt} \%$ plasticized poly(lactic acid) (PLA). The KBF was treated with various percentages of sodium hydroxide $(\mathrm{NaOH})$, whereas $5 \%$ triacetin was used as plasticizer. The effects of the KBF surface treatments on the tensile, flexural, impact strength, and DMA of the biocomposites were investigated. Tensile, flexural, and impact testing results reveal that $4 \%$ of $\mathrm{NaOH}$-treated $\mathrm{KBF}$ produced composites with optimum tensile strength $(62 \mathrm{MPa})$, flexural strength $(67 \mathrm{MPa})$, and the impact strength $(42 \mathrm{~kJ} / \mathrm{m} 2)$. The removal of the lignin from the fiber during the surface treatment caused the increment in the modulus result. This finding is also supported by the dynamic mechanical analysis. The storage modulus of plasticized PLA/treated KBF is higher than the storage modulus of plasticized PLA/untreated KBF which is attributed to the enhancement of the fiber-matrix adhesion. The loss modulus results showed that the $\mathrm{Tg}$ of the plasticized composites was shifting to higher temperature, from 55C for plasticized PLA/untreated $\mathrm{KBF}$ to $65 \mathrm{C}$ for plasticized PLA/treated KBF. The increase in Tg shows that the plasticized PLA has low chain mobility when reinforced with treated $\mathrm{KBF}$, indicating better interaction.
\end{abstract}

Keyword: Kenaf bast fiber; $\mathrm{NaOH}$; Plasticizer; Triacetin; Poly(lactic acid); Biodegradable. 